\title{
O Assédio Moral e seu Impacto no Desenvolvimento Organizacional
}

\author{
Aline Thaise Oliveira Amaral Feitosa ${ }^{1}$;Andressa Pacífico Franco Quevedo ${ }^{2}$
}

\begin{abstract}
Resumo: O presente trabalho contém uma análise do impacto do assédio moral no desenvolvimento das organizações, considerando a importância dos indivíduos em seu processo produtivo, na qual o assédio moral atua como um inibidor, desta forma, fez-se necessário estudar e explorar este tema pertinente nos dias atuais, que é um problema ameaçador que nasce, se fortalece e se dissemina no ambiente laboral, e trabalha silenciosamente como um sabotador dos interesses da organização, infiltrando-se em sua principal modeladora comportamental, comprometendo o seu processo de desenvolvimento. A pesquisa tipifica-se como bibliográfica e exploratória, pois permitiu-nos conhecer os temas em questão sob a perspectiva de diferentes autores e situações com o objetivo de analisar o impacto que o assédio moral tem no desenvolvimento organizacional, deste modo, discutiu-se, sobre: Assédio moral, estresse no trabalho, higiene do trabalho e cultura organizacional, o que permitiu descobrir que o assédio moral quando presente no contexto organizacional impacta negativamente o seu processo produtivo.
\end{abstract}

Palavras-chave: Assédio moral, estresse no trabalho, cultura organizacional.

\section{The Moral Harassment and its Impact on the Organizational Development}

\begin{abstract}
This work contains an analysis of the impact of bullying in the development of organizations, considering the importance of individuals in its production process, in which the bullying acts as an inhibitor in this way, it was necessary to explore and exploit this relevant topic nowadays, since it is a threatening problem that arises strengthens and spreads in the work environment, and works silently as a saboteur of the organization's interests, infiltrating in their main behavioral modeling, compromising their development process. The research typifies as bibliographic and exploratory, it allowed us to know the issues in question from the perspective of different authors and situations already registered in different literatures in order to analyze the impact that bullying has on organizational development, thereby we discussed about: Mobbing, work stress, work hygiene and organizational culture, which allowed to discover that this harassment in the organizational context negatively impacts in your production process of organizations.
\end{abstract}

Keywords: Moral harassment, work stress, organizational culture.

\section{Introdução}

A importância do indivíduo no contexto organizacional foi uma realidade reconhecida ao logo do processo da construção do pensamento administrativo com o surgimento da escola de Recursos Humanos, porém, a sua importância no contexto das organizações sempre existiu. Antes mesmo do

\footnotetext{
1 Especialização em Gestão Pública pela Universidade Federal do vale do São Francisco - UNIVASF . E-Mail: alinetahise.adm@ gmail.com

${ }^{2}$ Mestre em Administração pela Universidade Federal de Pernambuco (UFPE). Professora Assistente da Universidade Federal Rural de

Pernambuco. Especialista em Gestão da Capacidade Humana nas Organizações pela Universidade de Pernambuco (UPE). Graduada em Turismo pela Universidade Federal de Pernambuco (UFPE). E-mail: andressadm@gmail.com.
} 
surgimento da administração científica. Porque, todas as organizações são constituídas por pessoas e estas são indispensáveis para o seu funcionamento (CHIAVENATO, 2004).

São elas as responsáveis pela produtividade da organização, pois alavancam os seus processos produtivos as conduzindo ao seu desenvolvimento, sem elas as organizações não existiriam.

$\mathrm{Na}$ Área de Recursos Humanos ${ }^{3}$, até então o indivíduo era percebido no contexto organizacional com "recurso" unicamente, a nova ARH, percebe um indivíduo como pessoa, rompendo a antiga forma de gerenciamento de pessoas, como afirma Chiavenato (2004, p.59).

A ARH tem duas diferentes vertentes para considerar as pessoas: as pessoas como pessoas (dotadas de características próprias de personalidade e individualidade, aspirações, valores, atitudes, motivações e objetos individuais) e as pessoas como recursos (dotadas de habilidades, capacidades, destrezas e conhecimentos necessários para a tarefa organizacional).

Desta forma, é notória a relevância do indivíduo no contexto organizacional sob a perspectiva dele como pessoa e não apenas como recurso, assim, toda influência externa exercida de forma negativa sobre o indivíduo são prejudiciais tanto ele como a organização, pois é o indivíduo que faz a organização, atentar contra a sua saúde: física, emocional e psicológica e atentar contra a saúde da própria organização.

Relacionamentos abusivos no contexto laboral causam danos à capacidade produtiva do indivíduo, impactando assim diretamente à organização, pois compromete à sua capacidade produtiva; esta espécie de abuso oriunda do ambiente laboral é classificada de assédio moral:

\footnotetext{
O assédio moral é uma conduta abusiva, intencional, frequente e repetida, que ocorre no ambiente de trabalho e que visa diminuir, humilhar, vexar, constranger, desqualificar e demolir psiquicamente um indivíduo ou um grupo, degradando as suas condições de trabalho, atingindo sua dignidade e colocando em risco a sua integridade pessoal e profissional (BARRETO citado por FREITAS; HELOANI; BARRETO, 2008, p.180).
}

Assim, o estudo sobre o assédio moral, suas manifestações e reflexos no ambiente laboral é pertinente e relevante, pois implica no desenvolvimento organizacional, nenhuma forma de gerenciamento ou a mais efetiva ferramenta administrativa, terá efetividade em um ambiente onde o assédio moral não apenas está presente como é também ignorando, desta forma, o presente trabalho tem como objetivo a análise do impacto do assédio moral no desenvolvimento organizacional, sob a perspectiva da relação entre gestor e colaborador.

${ }^{3}$ A partir daqui trataremos Área de Recursos Humano como ARH 
Id on Line Revista Multidisciplinar e de Psicologia

Id on Line Multidisciplinary and Psychology Journal

\section{Procedimentos Metodológicos}

A tipologia do presente trabalho classifica-se como pesquisa bibliográfica que foi realizada com o auxílio de: livros, artigos, revistas, periódicos e etc.

Define-se como pesquisa bibliográfica aquela que se dá exclusivamente pelo uso de obras já existentes, como afirma Gil (2002, p.44) “A pesquisa bibliográfica é desenvolvida com base em material já elaborado, constituído principalmente de livros e artigos científicos", porém há outros tipos de pesquisas que possuem a necessidade da consulta bibliográfica, segundo Ruiz (1991, p. 57) “qualquer espécie de pesquisa, em qualquer área, supõe e exige pesquisa bibliográfica prévia.".

Lakatos e Marconi (2001, p.183) definem o conceito de pesquisa bibliográfica semelhantemente a definição proposta por Gil (2002).

a pesquisa bibliográfica, ou de fontes secundárias, abrange toda bibliografia já tornada pública em relação ao tema de estudo, desde publicações avulsas, boletins, jornais, revistas, livros, pesquisa, monografias, teses, material cartográfico etc.

Há diversas fontes de informações em diferentes obras bibliográficas, os mais comuns e utilizados são os livros, segundo Gil (2002, p. 44) “Os livros constituem as fontes bibliográficas por excelência", porém este tipo de pesquisa não se restringe a este tipo de fonte bibliográfica como citado anteriormente."

A principal função das pesquisas desta natureza "[...] é colocar pesquisador em contato direto com tudo o que foi escrito e filmado sobre determinado assunto, inclusive com referências seguidas de debates, que tenham sido transcritos por alguma forma, quer publicadas, quer gravadas." (LAKATOS; MARCONI, 2001, p.183). As classificações das fontes bibliográficas variam de acordo com os autores, apesar de ser uma transcrição de informação este tipo de pesquisa não é uma cópia do que foi mencionada anteriormente por outros autores, ela pode levar o pesquisador a uma análise diferenciada do mesmo tema, levando-o a novas conclusões (TRUJILLO, citado por LAKATOS; MARCONI, 2001). Este tipo de pesquisa proporciona uma visão ampla e uma nova percepção sobre o tema em questão, mediante a discussão e informações existentes.

Gil (2002, p. 41), afirma que a pesquisa exploratória “[...] Tem como objetivo proporcionar maior familiaridade com o problema, com vistas a torná-lo mais explícito ou a construir hipóteses. Pode-se dizer que estas pesquisas têm como objetivo principal o aprimoramento de ideias ou a descoberta de intuições".

Assim, o presente trabalho utilizou este tipo de pesquisas a fim de obter conhecimento para análise do tema apresentado considerando a sua relevância no contexto organizacional. 


\section{Assédio Moral}

O ato de violência quando presente no contexto organizacional é um sabotador do seu próprio desenvolvimento, neste sentido, todo recurso financeiro e tecnológico nela investido não possuirão efetividade, pois a alavanca que a movimenta, o indivíduo, está com sua capacidade produtiva comprometida, estando à organização desta forma, fadada a estagnação ou ao fracasso.

Paroski (2007, p. 216) define assédio e assediar da seguinte forma:

Assédio" significa, entre outras coisas, insistência inoportuna junto a alguém, com perguntas, propostas e pretensões, dentre outros sintomas. "Assediar", por sua vez, significa perseguir com insistência, que é o mesmo que molestar, perturbar, aborrecer, incomodar, importunar.

Percebe-se que o próprio assédio é um ato de violência, Warshaw (citado por NUNES; TOLFO, 2015, p.22,), define violência como: “[...] qualquer tipo de comportamento agressivo ou abusivo que possa causar um dano ou desconforto físico ou psicológico em suas vítimas, sejam essas alvos intencionais ou envolvidas de forma impessoal ou incidental".

Durante este ato de violência de origem laboral a vítima é colocada em uma posição de desamparo e incapacidade que é fortalecido pelas ações hostis do agressor, que a depender da cultura organizacional pode favorecer e intensificar a violência.

O assédio moral envolve comunicação hostil e não ética, direcionada de um modo sistemático por um ou mais indivíduos para um alvo que, durante essa violência, é posto em uma posição desamparada e indefesa, sendo mantido nesta condição por meio de ações hostis (LEYMANN, citado por NUNES e TOLFO, 2015, p.23).

Hirigoyen (citado por FERREIRA, 2006, p. 183) define assédio moral de forma similar:

[...] toda e qualquer conduta abusiva, manifestando-se sobretudo por comportamentos, palavras, atos, gestos, escritos que possa trazer dano à personalidade, à dignidade ou à integridade física ou psíquica de uma pessoa, pôr em perigo seu emprego ou degradar o ambiente do trabalho.

Ambas as definições dos autores definem o assédio moral como um ato violento. Segundo, Nunes e Tolfo (2015), esta violência pode partir de qualquer indivíduo da organização, independente de sua posição hierárquica, destas formas os autores classificam a relação de violência da seguinte forma:

- Vertical descendente

- Incide do superior ao subordinado

- Vertical ascendente

○ Ocorre do subordinado ao superior

\section{- Horizontal}

- Advém dos colegas, isto é, indivíduos com as mesmas posições hierárquicas. 
Embora haja estas três formas de incidência do assédio moral, a mais praticada no Brasil é a de incidência descendente, com índices que chegam a 90\% (NUNES e TOLFO, 2015); independente de onde parte a violência, este ato, também pode ser classificado quanto à finalidade do ato:

a) assédio perverso: exercido com o objetivo da eliminação do outro ou a valorização do próprio poder, neste caso como uma forma de se engrandecer o superior sente a necessidade de rebaixar os demais; b) assédio estratégico: tem o intuito de forçar o alvo a pedir demissão, gerando assim um processo de dispensa sem "prejuízos" para a organização; c) assédio institucional: um instrumento/forma de gestão disciplinadora do coletivo. (citado por NUNES e TOLFO, 2015, p.25).

O assédio moral não beneficia a organização nem o indivíduo, as consequências neste ultimo caso são amplas e profundas e podem ser duradouras, pois este ato de violência possui um impacto tão significativo na vida da vítima que afeta a sua própria identidade.

A destruição da identidade do indivíduo vítima de assédio moral no trabalho ocorre rapidamente prejudicando, assim, o contexto de sua vida pessoal. No entanto, sua recuperação e inserção novamente na sociedade e no ambiente de trabalho pode levar anos. (MARTININGO FILHO; SIQUEIRA citado por NUNES; TOLFO, 2015, p.31).

As consequências do assédio moral ultrapassam os limites da organização, embora seja um problema de origem laboral, ela se estende à vida da vítima, se tornando ainda mais danosa, como afirma Nunes e Tolfo "As consequências e efeitos do assédio moral não ficam em torno do ambiente laboral, mas repercutem e afetam em aspectos da vida pessoal da vítima" (citado por NUNES; TOLFO, 2015, p. 31).

Considerando a incidência deste ato violento predominante no Brasil, o assédio descendente, com índices significativos é perceptível como é comum à falta de qualificação das pessoas que ocupam cargos de liderança no Brasil, de tal forma a gerar esta estatística tão significativa sobre um aspecto negativo na gestão e consequentemente, no ambiente laboral.

O fato mais pertinente na incidência deste ato é a forte influência do comportamento do gestor na construção da cultura organizacional, devido a sua posição de liderança, isto é, não é um ato que envolve duas pessoas apenas e faz uma vítima, quando este tipo de violência é uma característica da gestão, ela consequentemente torna-se parte da cultura organizacional, sujeitando todos na organização a este ato, como afirma Amaral (2013, p.70) "[...] a cultura se inicia com um fundador que constrói os valores e princípios da organização e reflete a gestão, gerando a cultura, que por sua vez, modela o comportamento humano, mas precisamente de seus colaboradores".

Conhecendo a forte influência do gestor no processo da formação da cultura organizacional, um gestor portador de um comportamento violento tenderá a gerar uma cultura onde o ato do assédio moral seja um ato comum, desta forma esse tipo de comportamento é inadmissível para 
toda a sociedade sob a perspectiva do código de ética, porém, no dia a dia, o que teoricamente e eticamente é inadmissível, torna-se corriqueiro e natural, pois uma cultura que proporcione a ação e manutenção de comportamentos violentos promovem novas crenças nos indivíduos que fazem parte dela, desconstruindo outros. Como afirma Daff (2002, p.293) referente à cultura organizacional "cultura é o conjunto de valores, crenças orientadoras e modos de pensar compartilhado pelos membros de uma organização e transmitido aos novos membros como adequados."

Desta forma, não apenas o gestor gera o ato, como o seu ato conduz os demais colaboradores da organização a aderirem este comportamento, como a cultura envolve construção de crenças, os colaboradores mesmo com convicções e crenças éticas que entendem por inaceitável tal comportamento, submetido a uma cultura que valoriza o assédio, onde este ato de violência é comum, esta nova realidade passa a influenciá-los na construção de novos conceitos sobre estes indivíduos.

O ambiente laboral não pode ser percebido e aceitado como um cenário de terrorismo, atos violentos precisam ser banidos, para assegurar a integridade não apenas física do indivíduo, mas também, psicológica. As organizações públicas ou privadas têm a responsabilidade e o dever de promover um ambiente que promova a saúde e o bem estar dos indivíduos, que devem ser percebidos nas organizações como pessoas, indivíduos dotados de perspectivas, sentimentos e etc.; e não apenas como recurso, indivíduos passivos e "coisificados"; enquanto o indivíduo não for reconhecido como pessoa no contexto organizacional, esta prática de violência se propagará e se intensificará.

Apesar de todo mal causado pelo assédio moral no indivíduo e na organização, o mais preocupante em relação à manifestação, intensificação e disseminação deste ato é não formalização da denúncia por parte das vítimas assim que é percebido o assédio, este comportamento, favorece a intensificação do ato e conseguinte sua disseminação por parte do agressor, vulnerabilizando mais a vítima. "O assédio moral nas organizações, geralmente, nasce de forma insignificante e propaga-se pelo fato de as pessoas envolvidas (vítimas) não quererem formalizar a denúncia e encararem-na de maneira superficial, deixando passar as insinuações e as chacotas [...]" (FREITAS, 2001, p.10).

É importante salientar, que o assédio moral, para ser caracterizado de tal forma precisa de dois elementos principais, que são a repetição do ato e a perseguição pessoal, dos quais devem se prolongar por um tempo, pois conflitos que ocorrem isoladamente, ainda que enseje dano moral, não pode ser caracterizado como assédio moral.

O intrigante é que o assédio mais incidente no Brasil é vertical descendente, desta forma incide a qual o subordinado é a vítima e o superior o agressor, sendo que compete a este último conduzir os indivíduos da organização a alcançar objetivos estabelecidos por ela em prol dela, porém, quando o gestor exerce o assédio, ele deixa de gerenciar as pessoas em prol da organização e passa a dirigi-los em prol de objetivos pessoais, visto que esse comportamento violento compromete a organização e satisfaz apenas os objetivos pessoais do agressor. 
Neste contexto a pergunta eminente é: A verdadeira ameaça para as organizações com líderes nestas condições está fora ou dentro dela? É notório que um indivíduo com tais características sobre o poder atrelado a um cargo de liderança pode fazer à organização; em situações assim, não haverá recurso, estratégia ou tecnologia capaz de dar os resultados esperados no contexto organizacional, se este problema não for identificado e solucionado.

Pode-se perceber o quanto indivíduos assediadores empossados em cargos de liderança podem comprometer a produtividade da organização, pois o fato é que ela trava sua principal alavanca, pois as principais pessoas que se tornam alvos destas ações são pessoas com características que representam grande potencial para empresa, enquanto o potencial dente indivíduo é favorável ao desenvolvimento organizacional, o mesmo potencial representa uma ameaça ao assediador, o objetivo do assédio moral é eliminar a vítima, desta forma enquanto a organização manter o indivíduo com potencialidades o assediador quer removê-lo, considerado ainda neste caso a forma de assédio vertical descendente.

As vítimas, indivíduos disponíveis à mudança e à autocrítica, empáticos, éticos e com capacidade para a liderança informal, são percebidas como ameaças pelos agressores (indivíduos "menos capazes" ou que apresentam transtornos de personalidade ou alterações psicopáticas) e tornam-se alvos de ameaças, críticas infundadas, calúnias, manipulações e estigmatizações frente aos demais companheiros de trabalho. (CANIATO e LIMA, 2008, p. 182).

Em tais situações selecionar, promover e manter indivíduos que exercem o ato violento do assédio nestes cargos de liderança é um boicote à própria organização, à sua saúde e desenvolvimento.

\section{Higiene no Trabalho}

O indivíduo alavanca o processo produtivo das organizações, pois são eles quem a movimenta diariamente com o desenvolvimento de suas atividades, independente do nível em que ela é realizada: Operacional, tático ou estratégico; os estímulos externos exercem grande influência sobre o indivíduo, trabalhar o ambiente externo para gerar bem estar nas pessoas desencadeará em saúde para os colaboradores, de igual forma se o ambiente oferecer estímulos negativos causará mal estar aos colaboradores, logo poderá desencadear doenças, o que implicará na produtividade organizacional; considerando que colaboradores saudáveis, formam uma organização saudável, colaboradores doentes, formam organizações doentes.

Classifica-se os estímulos externos compostos pelo ambiente no qual o colaborador está inserido em higiene do trabalho, segundo Chiavenato (2010, p.470) "A higiene do trabalho esta relacionada com as condições ambientais de trabalho que assegurem a saúde física e mental e com as 
condições de saúde e bem-estar das pessoas". Desta forma percebemos que o ambiente externo exerce não apenas influência sobre o físico do indivíduo, mas sobre a mente, partindo para questões mais profundas do indivíduo que vai além do alcance física, influem no: pensamento, percepção, sensação e sentimento. A higiene do trabalho pode ser percebida sob dois pontos de vista: física e mental.

Do ponto de vista físico, são considerados todos os aspectos relacionados aos agentes externos que o indivíduo está exposto, perceptível aos cinco sentidos humano: olfato, audição, paladar, tato e visão, segundo Chiavenato (2010, p. 470).

Do ponto de vista de saúde física, o local de trabalho constitui a área de ação da higiene do trabalho, envolvendo aspectos ligados com a exposição do organismo humano a agentes externos como ruído, ar, temperatura, umidade, luminosidade e equipamentos de trabalho. Assim, um ambiente saudável de trabalho deve envolver condições ambientais físicas que atuem positivamente sabre todos os órgãos dos sentidos humanos como visão, audição, tato, olfato e paladar.

Do ponto de vista mental, estão os fatores relacionados à saúde mental do indivíduo, são os estímulos que exercem influência sobre o comportamento, que abrangem os pensamentos, o seu processo de percepção, seus sentimentos e como ele sente o ambiente, como afirma Chiavenato (2010, p.470):

Do ponto de vista de saúde mental, o ambiente de trabalho deve envolver condições psicológicas e sociológicas saudáveis e que atuem positivamente sabre o comportamento das pessoas evitando impactos emocionais, como o estresse.

Logo, ressalta-se que a higiene do trabalho é um procedimento administrativo e estratégico para o desenvolvimento da organização, pois proporciona saúde para seu principal componente de produção, seus colaboradores; desta forma, a higiene do trabalho permite condições da organização usar o seu recurso humano de forma plena, investido as suas habilidade: conceituais e técnicas a favor da organização.

\section{A parte imaterial do indivíduo: a mente}

A Psicologia andou sempre ao lado da filosofia não é atoa de que seus precursores foram os filósofos: Sócrates, Platão e Aristóteles e outros. O termo psicologia passou apenas a ser comum no século XIII, embora ela tenha passado a ser ciência há apenas 130 anos, a necessidade que o homem tinha de se entender, sempre existiu (BERTOLDI, 2011). No sentido etimológico da palavra, Psicologia vem do grego: $\log o s$, "razão" e psyché, "alma", ou seja estudo da alma.

Depois que o termo Psicologia se tornou comum no século XVIII, a palavra passou a significar estudo da "mente" (BERTOLDI, 2011) desta forma, podemos então perceber que os termos: 
alma e mente neste sentido referem-se à mesma coisa ${ }^{4}$. Os gregos entendiam que a alma era a parte imaterial do ser humano, isto é, a parte não visível: pensamentos, sentimentos, sensações, percepção.

\section{O estresse no trabalho}

O conceito do estresse no trabalho é semelhante ao de higiene no trabalho; ambos os assuntos possuem correlação e referem-se à influência dos estímulos externos sobre o qual indivíduo está exposto. Chiavenato (2011, p. 473) define o estresse como: “[...] um conjunto de reações físicas, químicas e mentais de uma pessoa decorrente de estímulos ou estressores que existem no ambiente".

Para Correia e Menezes (2002) o estresse se desencadeia quando o indivíduo se julga não sendo capaz de cumprir as demanda imposta pela sociedade, o fazendo sentir que seu papel social está ameaçado, desta forma o organismo responde de modo a dominar estas demandas impostas, a função natural do estresse seria nesta situação o preparar para luta ou para a fuga, porém este não é um comportamento adequado do ponto de vista da adaptação humana; desta forma quando o indivíduo entra em contato com o agente estressor no trabalho, não pode manifestar sua reação, assim, ele se torna prisioneiro do medo ou da agressão, e é forçado a produzir um comportamento emocional incoerente com a sua realidade.

Percebe-se que o estresse então, parte da influência do ambiente sobre o indivíduo, compreendendo essa forte poder exercido pelo ambiente sobre o indivíduo, surge à necessidade de formatar o ambiente de trabalho em consonância com a saúde humana, isso, irá beneficiar a ambos envolvidos nesta relação de troca, de: organização e colaborador.

É também notório na definição de Chiavenato (2011) que o estresse gera reações físicas, químicas e mentais, isto é, influencia diretamente no comportamento do colaborador, o levando a se comportar da forma que o estímulo o conduzir, se o ambiente não possui condições que promovam o bem estar deste colaborador, isso resultará em comportamento adverso aos objetivos da organização, se o ambiente, estimular um comportamento favorável, entusiasmará de forma positiva a organização.

Esse tipo de estresse quando desenvolvido no ambiente laboral é definido como estresse ocupacional, como classificam Paschoal e Tamayo "O estresse ocupacional enfoca estressores relacionados ao ambiente de trabalho, e os de forma geral estressores gerais na vida do indivíduo" (citado por BENKE e CARVALHO 2008, p.02), desta forma, a organização tem de adotar medidas preventivas ao desenvolvimento deste tipo de estresse em seus colaboradores, essas medidas preventivas, podem ser entendidas como a higienização do ambiente de trabalho nas formas: física e mental.

${ }^{4}$ A partir daqui vamos usar o termo "alma" como sinônimo de "mente" 
O fator socialização se enquadra nos estímulos externos que alcançam diretamente a mente do indivíduo, um ambiente de socializações falidas demostram a ausência de higiene laboral sob a perspectiva mental, desta forma, ela também exerce poder sobre o comportamento do indivíduo, pois em uma relação, os envolvidos exercem ou sofrem influência, a partir deste ponto, entende-se a importância de uma relação saudável entre o gestor e o seus colaboradores, pois o gestor exerce forte alcance sobre seus colaboradores, não é atoa que, colaboradores que não possuem um relacionamento saudável com seu gestor, podem apresentar reações adversas e indesejadas pela organização, como afirma Chiavenato (2011, p.473). “[...] relações problemáticas com chefes ou clientes que provocam reações como nervosismo, inquietude, tensão etc."

Compreende-se então, que a ação do gestor sobre os seus colaboradores pode ser boa ou ruim, cabe a ele promover saúde no trabalho e não doenças, começando pela forma com que ele se relaciona com seus colaboradores e abrangendo as demais áreas da organização, pois os hábitos organizacionais, desde a forma de socialização aos procedimentos burocráticos, estão totalmente ligados à cultura organizacional, da qual o líder é o seu maior influenciador, isto é, ele a constrói com o seu poder atrelado a ele, desta forma, se o gestor de uma organização deseja resultados positivos deve gerenciar o ambiente externo removendo os estímulos negativos e trabalhando os positivos, de forma a promover bem estar.

\section{Cultura Organizacional}

A cultura no contexto organizacional possui grande relevância, pois ela impacta diretamente o comportamento humano. Daft (2002, p.293) define cultura da seguinte forma:

Cultura é o conjunto de valores, crenças orientadoras, conhecimentos e modos de pensar partilhado pelos membros de uma organização e transmitido aos novos membros como adequado. Ela representa a parte não escrita, o sentimento da organização. Todos participam da cultura, mas, em geral ela passa despercebida.

Morgan define cultura organizacional semelhantemente a Daft:

[...] cultura organizacional pode ser entendida como um processo de construção e compartilhamento da realidade organizacional, por meio do qual eventos, expressões e manifestações culturais são significados pelos empregados. (citado por JÚNIOR E ANDRADE, 2004, p. 192).

Em ambos os conceitos apresentados pelos autores à cultura organizacional é entendida como um processo de construção das crenças que nortearam comportamento de seus colaboradores; a cultura influencia o comportamento de todos que estão sob ela, e não de um indivíduo isoladamente, pois o seu processo inclui a partilha da percepção da realidade organizacional por ela construída. 


\title{
Segundo Mintzberg (citado por PIRES; MACÊDO, 2006 p.88)
}

[...] a cultura organizacional é a base da organização. São as crenças comuns que se refletem nas tradições e nos hábitos, bem como em manifestações mais tangíveis histórias, símbolos, ou mesmo edifí- cios e produtos. Para o autor, a força de uma cultura está em legitimar as crenças e os valores compartilhados entre os membros de uma organização.

Na perspectiva gerencial a cultura é um instrumento manipulável, desta forma, pode ser usada para favorecer ou não aos objetivos da organização, depende de como ela será usada, segundo de Dupuis (citado por PIRES e MACÊDO, 2006, p.88)

\begin{abstract}
Visão gerencial. Considera que a cultura é mais uma das características que a organização possui. Trata-se de uma visão instrumental que vê a cultura como algo que pode ser manipulado pelos dirigentes da organização de acordo com a sua vontade. Vários autores que trabalham nesta abordagem vêem a cultura como uma variável quantificável e manipulável.
\end{abstract}

Conclui-se que a cultura é uma ferramenta moldadora do comportamento humano, desta forma, leva os indivíduos a um comportamento induzido, do qual independe da consciência da organização, como afirma Daft "a cultura estimula normas e convicções que sustentam a capacidade da organização para detectar, interpretar e traduzir sinais do ambiente em novas respostas comportamentais" (2002, p. 297).

Desta forma, a cultura é uma ferramenta administrativa poderosa, pois pode levar mediante o seu uso o indivíduo desenvolver um comportamento favorável, em relação aos objetivos da organização.

Embora a cultura impacte fortemente o comportamento humano podendo ser uma forte aliada no desenvolvimento organizacional, o seu poder pode ser destrutivo, por isso, ela precisa ser trabalhada de forma adequada para gerar resultados favoráveis, o que naturalmente é esperado por qualquer organização, caso contrário ela trará resultados não satisfatórios e danosos à organização.

Schein (citado por GOMES, 2000, p.03) em sua definição de cultura fortalece a definição dos autores mencionados anteriormente e percebe-se que em todas as definições apresentadas pelos autores, o principal objetivo da cultura está em definir e gerar comportamentos.

\footnotetext{
Um padrão de premissas básicas compartilhadas que o grupo aprendeu à medida que resolvia seus problemas de adaptação externa e integração interna, que funcionou suficientemente bem para ser considerada válida e, portanto, para ser ensinada aos novos membros como o meio correto de perceber, pensar e sentir em relação àqueles problemas.
}

Vale salientar que independente da gestão ser ou não consciente do poder da cultura no contexto organizacional, ela é construída, e está em constante atividade e provocando impactos no 
ambiente laboral, que podem ser benéficos ou não; e este processo de existência e construção independe da vontade da organização e do gestor. Desta forma, a cultura é um componente que não é visível na organização, porém, não pode ser ignorado, deve ser considerado com o valor e importância que ela possui.

Desta forma, é imaginável o estrago que uma cultura com crenças orientadoras e valores desfavoráveis ao desenvolvimento organizacional pode causar, portanto, trabalhar o perfil da cultura organizacional é indispensável, isto inclui trabalhar também o principal influenciador dela, o gestor, pois este é o responsável por difundir e disseminar crenças e valores que ela levará.

Embora as ideias que passam a integrar a cultura possam provir de qualquer lugar da organização, a cultura de uma organização começa com um fundador ou líder pioneiro que articula e implementa ideias e valores particulares como uma visão, filosofia ou estratégia empresarial (DAFT, citado por AMARAL, 2013, p.24 ).

Conclui-se, que um gestor que possui um comportamento violento desenvolverá uma cultura baseada em crença que instigará o desenvolvimento de comportamentos agressivos em seus colaboradores, gerando assim, um ambiente propício à disseminação e manutenção de atos violentos, onde a percepção da organização em relação a estes atos pode ser de naturalidade; comportamentos desta natureza vão de encontro com os objetivos da organização, bem como a saúde mental e física de seus colaboradores, que são expostos a um ambiente sem higiene laboral sob a perspectiva mental.

Prontamente, devido a forte influência do gestor na formação da cultura organizacional percebe-se, a necessidade da existência de pessoas qualificadas para ocuparem os cargos de liderança e assim, promover ganhos na perspectiva da empresa, sob a efetividade da gestão.

Neste contexto, as organizações públicas tendem a comprometer sua efetividade com a gestão ineficaz da cultura organizacional, como a maior parte do processo de ocupação dos cargos de liderança nesta esfera, se dá por meio de nomeação, este processo de seleção não assegura a competência do indivíduo nomeado, comprometendo os resultados de desenvolvimento organizacional, outro problema atrelado a este processo de seleção.

A organização da burocracia no Brasil, desde seus primórdios, foi afetada pelo uso corriqueiro das contratações fora do sistema do mérito para posições "temporárias" ou precárias, da burla ao concurso público, como forma de ingresso nos cargos e empregos permanentes. Como contraponto, deu-se, historicamente, o uso das formas de livre provimento para o exercício de cargos "de confiança" voltando a permitir que, a cada momento, os dirigentes dos órgãos e entidades públicas pudessem ser selecionados segundo os critérios de confiança e conveniência dos detentores do poder político (SANTOS, 2009, p.11)

O processo de nomeação além de não assegurar qualificação dos indivíduos muitas vezes admitidos nos cargos de liderança, também influencia na intensa rotatividade do pessoal, ambas as 
questões geram consequências negativas à cultura organizacional; pois, quando um gestor em cargo de nomeação ele começa a estabelecer uma cultura organizacional, porém, devido a instabilidade dos cargos, se no meio do processo, este gestor fosse removido do processo e substituído por outro, com crenças, valores, princípios e etc. diferentes de seu antecessor, a cultura se consolidaria em valores e crenças confusas devido a ruptura de normas, crenças e valores estabelecidas em um momento por um indivíduo e contrariada ou desfeita por outro, isto é, o novo nomeado.

Devido à instabilidade e a ausência de segurança imposta pelo processo de nomeação para cargos de liderança no setor público, o ambiente favorece ao desenvolvimento de atos violentos no ambiente de trabalho, que se refletem na organização sob a forma da cultura organizacional, o problema em questão, é que a cultura leva anos para se consolidar de igual forma para desconstruí-la, porque se trata de um processo que envolve crenças e valores de vários indivíduos. Assim, este sistema de nomeação garante a construção de uma cultura pré-disposta ao desenvolvimento de atos violentos, como o assédio moral, pois não garante á qualificação das pessoas selecionadas para assumirem os cargos de liderança e que independente desse fator ser percebido como relevante para o desenvolvimento da organização pela administração pública, a cultura organizacional permanece em constante atividade, operando e se formando, independente das circunstâncias e gerando com ela impactos organizacionais.

Como o processo de nomeação é vigente no Brasil como uma forma de seleção para cargos de liderança, e com este processo vem atrelada a inconstância dos indivíduos em seus cargos, naturalmente sempre se encontrará nestes órgãos uma cultura confusa, sem definição, isto é, clareza de valores, crenças e princípios norteadores, e o pior, o processo de construção desta cultura marcada pela grande rotatividade e desqualificação da maior parte de seus profissionais, que é mais complexo.

\section{Considerações Finais}

O ambiente possui forte influência sobre o indivíduo, prezar por um ambiente higiênico na perspectiva física e psicológica do indivíduo, deve ser encarada pelo gestor, não como opção e sim obrigação, não como despesa, mas investimento em longo prazo.

Um ambiente que possui higiene psicológica está imune de agentes estressores, capazes de levar o desencadeamento de comportamentos indesejáveis pelos colaboradores, comprometendo desta forma sua produtividade; dentro deste grupo de agentes estressores podem ser mencionados os indivíduos que ocupam cargos de liderança ou façam parte da mesma posição hierárquica; no primeiro caso o agressor passa a possuir mais significância e agravar o estado de estresse natural e com ele evoluindo o impacto de seu ato violento sobre a vitima, quando estas ações de hostilidade são 
repetitivas e pessoais, há uma evolução deste estresse para um quadro que se caracteriza como: assédio moral, o impacto deste último sobre a vitima é mais intenso e profundo.

As consequências do assédio moral são danosas à vida da vítima, não apenas profissional, mas a também a pessoal, ultrapassando os limites da organização, em situações de assédio moral, o indivíduo assediado, não é o único afetando, mas a própria organização, pois inibe a produtividade do(s) dos indivíduos e eles constituem o bem mais precioso para a organização, são eles os reesposáveis por alavancar a sua produtividade e gerar desenvolvimento.

A questão mais preocupante no contexto organizacional sobre este tema é a admissão, promoção ou manutenção de pessoas assediadoras em cargos de liderança, a qual possui por função, conduzir efetivamente os colaboradores da organização a alcançarem um objetivo comum a todos, isto é, os objetivos organizacionais, as quais a empresa precisa atingir para sobreviver e se desenvolver no mercado, nesta situação, o assediador ocupando uma posição de liderança, trabalha o contrário e não a favor da organização, porque a sua pratica violenta de assedio, possui finalidades pessoais se opondo naturalmente as reais finalidades de seu cargo no contexto organizacional, visto que são as pessoas que possuem potencialidade para a empresa que geralmente são suscetíveis ao assédio, pois o sua virtude tão prezada e estimada pela organização passa a ser uma ameaça para o gestor assediador, enquanto por um lado a empresa quer manter este colaborador na organização o gestor assediador que eliminálo, havendo o próprio boicote da empresa.

A maior incidência de assédio moral no Brasil ocorre de superiores para subordinados, um dado preocupante para as organizações brasileiras, pois tais cargos possuem um grande poder atrelado a ele sobre os colaboradores, isto é, a influência exercida pelo superior sobre a organização; além deste alcance e poder, é o líder, a principal peça na construção da cultura organizacional, que é responsável por gerar as crenças, valores e princípios da organização, sendo ela quem modela o comportamento humano no contexto organizacional; desta forma, ela pode ser entendida como uma ferramenta geradora de novos assediadores, manter e compartilhar a ideia de naturalidade deste ato, adoecendo a empresa, a resolução para este problema reside exclusivamente na sua identificação e resolução (eliminado os assediadores destes cargos de liderança) e uma nova percepção da gestão para a implementação de práticas inibidoras destes atos no contexto da organização.

\section{Referências}

AMARAL, Aline Tahise Oliveira. Do Motivo à Ação: O Comportamento Humano e o Impacto no Desenvolvimento Organizacional. 2013. fls 86. Monografia. Faculdade Sete de Setembro, Paulo Afonso, 2013. 
BENKE, Mara Regina Pagnussat; CARVALHO, E. Estresse x qualidade de vida nas organizações: um estudo teórico. Rio de Janeiro (RJ): FESURV, 2008.

BERTOLDI, Alexandra Danuza. Psicologia Organizacional. Centro universitário Leonardo da Vinci: Indaial, grupo UNIASELVI, 2011.x; 257.p.: il

CANIATO, Angela Maria Pires; LIMA, Eliane da Costa. Assédio moral nas organizações de trabalho: perversão e sofrimento. Cadernos de Psicologia Social do Trabalho, v. 11, n. 2, p. 177-192, 2008.

CHIAVENATO, Idalberto Gestão de pessoas: o novo papel dos recursos humanos nas organizações. - 3. Ed.- Rio de Janeiro: Elsevier, 2010.

CHIAVENATO, Idalberto. Recursos Humanos: O capital humano das organizações. 8. Ed. São Paulo: Atlas, 2004.

CORRÊA, Sebastião Augusto; MENEZES, José Ricardo de Melo. Estresse e trabalho. Campo Grande: Monografia de Pós-Graduação Lato Sensu, Sociedade Univesitária Estácio de Sá, 2002.

DAFT, Richard. Organizações: Teoria e Projetos. 7. Ed. São Paulo: Afiliada, 2002.

DE SOUZA PIRES, José Calixto; MACÊDO, Kátia Barbosa. Cultura organizacional em organizações públicas no Brasil. RAP Rio de Janeiro, v. 40, n. 1, p. 81-105, 2006.

FERREIRA, João Batista et al. Situações de assédio moral a trabalhadores anistiados políticos de uma empresa pública. Psicologia em Revista, v. 12, n. 20, p. 215-233, 2006.

FREITAS Maria Ester, HELOANI Roberto e BARRETO Margarida. Assédio moral no trabalho. Psicologia política. VOL. 8. Nº 15. PP. 179 - 182. JAN - JUN 2008.

FREITAS, Maria Ester de. Assédio moral e assédio sexual: faces do poder perverso nas organizações. Revista de Administração de Empresas, v. 41, n. 2, p. 8-19, 2001

GIL, Antônio Carlos. Como Elaboras Projetos de Pesquisa. 4 ed. São Paulo. Atlas, 2002.

GOMES, Adelino D. Cultura organizacional. Comunicação e Identidade, 2000.

JUNIOR, Francisco Antonio Coelho; BORGES-ANDRADE, Jairo Eduardo. Percepção de cultura organizacional: uma análise empírica da produção científica brasileira. Psico-USF, v. 9, n. 2, p. 191199, 2004

LAKATOS, Eva Maria; MARCONI, Marina de Andrade. Fundamentos de Metodologia Científica. 4 ed. São Paulo. Atlas, 2001.

NUNES Thiago Soares e TOLFO da Rosa. O Assédio Moral No Contexto Universitário: Uma Discussão Necessária. Revista de Ciências da administração, v.17, nº 41, p.21-36 abr.2015.

PAROSKI, Mauro Vasni. Assédio moral no trabalho. Revista Jus Navigandi, 2007.

RUIZ, João Álvaro. Metodologia Científica: Guia para eficiência nos estudos. $3^{\mathrm{a}}$. ed. São Paulo: Atlas, 1991.

SANTOS, Luiz Alberto dos. Burocracia profissional e a livre nomeação para cargos de confiança no Brasil e nos EUA. 2009. 
Id on Line Revista Multidisciplinar e de Psicologia

Id on Line Multidisciplinary and Psychology Journal

\section{Como citar este artigo (Formato ABNT):}

FEITOSA, A.T.O.; QUEVEDO, A.P.F. O Assédio Moral e seu Impacto no Desenvolvimento Organizacional. Id on Line Revista Multidisciplinar e de Psicologia, Julho de 2016, vol.,10 n.30, Supl 1. p. 320-335. ISSN 1981-1179.

Recebido: $16 / 06 / 2016$

Aceito: $21 / 06 / 2016$ 